\title{
Door opens for national labs
}

\section{Tokyo}

A BUREAUCRATIC wall that has prevented effective collaboration between researchers in Japan's universities and national research laboratories is about to crumble.

In Tsukuba science city north of Tokyo, a newly proposed scheme will allow researchers from 30 national research institutes affiliated to seven different government agencies and ministries to take up positions as visiting professors or assistant professors at Tsukuba University in order to supervise graduate students. To Western eyes, this may seem unremarkable, but in Japan it is almost revolutionary and indicates a new willingness on the part of Japan's various government agencies and ministries to cooperate in research.

Until very recently, the Ministry of Education, Science and Culture (MESC), which runs Japan's national universities, has steadfastly guarded its territory and refused to allow non-MESC researchers to participate in university research. In particular, the supervision of graduate students has been strictly limited to university faculty members.

This damaged Japanese research in at least two ways. First, the national laboratories have not been able to bring in new, young researchers, as clampdowns on hiring have combined with the unavailability of graduate student workers to magnify the effect.

Second, graduate students in universities have not had access to the newer, better facilities of the national laboratories and have had to make do with the often outmoded equipment of the universities.

Now, Tsukuba may open the way for graduate students to work with scientists from the national laboratories. Although Tsukuba University is the only exception so far to MESC's rules, all the major national research institutes have locations in Tsukuba and thus will have access to graduate students there. And some observers see the recent move as a sign that MESC is becoming more flexible.
The first crack in MESC's bureaucratic wall actually appeared in 1988 , when the ministry established a new graduate university where researchers from MESC national research institutes could supervise graduate students and award degrees (see Nature 333, $290 ; 1988)$. There are only a handful of MESC institutes involved in the graduate university, however, and the ministry still refused researchers from other national laboratories the right to train graduate students. Another breach was made last year when MESC allowed Saitama University to appoint visiting professors and assistant professors from the Institute of Physical and Chemical Research (RIKEN) in Wako city in the outskirts of Tokyo - RIKEN is a 'special corporation' ( tokushuhojin) affiliated to the Science and Technology Agency that enjoys unusual freedom from bureaucratic control. Once again, however, this involved only a few researchers, and as RIKEN is not a normal national laboratory, this move did not automatically imply an opening for other institutes.

Nonetheless, Yoshimasa Yoshizawa, vice president of Tsukuba University, says that the RIKEN-Saitama agreement was the 'driving force' for the new Tsukuba scheme. And he says he was pleasantly surprised by the ease with which MESC accepted Tsukuba's plan. "Five years ago it would probably have been a lot more difficult," he says.

Under the scheme, about 50 researchers from Tsukuba national laboratories will be appointed to the university from next fiscal year and will each supervise one or two graduate students in their respective laboratories. A handful of researchers will also be drawn from private company research laboratories in Tsukuba, including institutes belonging to Takeda and Eisai pharmaceutical companies. But although there are now 140 private-sector laboratories in Tsukuba, Yoshizawa does not expect many companies to join the scheme. Most private companies, he says, do not wish to disclose their proprietary research results.

\section{National lab researchers dissatisfied}

GOVERNMENT researchers in Tsukuba science city may have broken through one bureaucratic barrier (see above), but most young researchers in Japan's national laboratories are still dissatisfied with their lot, according to a survey released last week by the Science and Technology Agency.

The survey was carried out by sending a questionnaire through several electronic mail computer networks used by scientists in Tsukuba and other regions of Japan. Eighty researchers, who are in their thirties and forties and come mainly (75 per cent) from national research laboratories, replied. More than half (43) are from Tsukuba.
When asked if satisfied with their job, 70 per cent said "no". Among the reasons given were: "I cannot do the research I want to do" (18 per cent); "I cannot get satisfactory results easily and have a lot of worries about my research" (16 per cent); and "salary and working conditions are poor" (22 per cent).

More than half of the respondents (56 per cent) said they would gladly move elsewhere if recruited. Among the suggestions of what should be done to improve conditions in the laboratory the most popular reply (30 per cent) was a call for introduction of flexible working hours (flexitime). D.s.
Yoshizawa says that when government officials planned Tsukuba science city in the 1960 s, they expected some interaction between the closely grouped government research laboratories and Tsukuba University. But in fact, although many researchers have informal contacts through research clubs and societies, very little formal cooperative research has been possible because of the bureaucratic barriers between the various ministeries and agencies that run research organizations in Tsukuba.

The scheme has yet to get formal approval from MESC and the Ministry of Finance.

David Swinbanks

\section{ACID RAIN}

\section{An economic case for environmental cooperation}

\section{London}

Wiтночт an unprecedented degree of economic co-operation, the countries of Europe could collectively waste more than $\$ 20,000$ million a year in relieving the damaging effects of acid rain across the continent, according to an economic analysis done by Bo Döös, deputy director of the International Institute for Applied Systems Analysis (IIASA).

Merely to keep the damage of acid rain across the continent from getting worse, Europe's sulphur dioxide emissions must be cut by $60-80$ per cent, Döös says. This could be achieved in a number of ways. The simplest - each country cutting its emissions by some 70 per cent - would cost some $\$ 31,000$ million a year. But the same result could be achieved for only about $\$ 9,000$ million a year, Döös says, by focusing the cuts in emissions more carefully.

In this case, the cuts would be concentrated in those countries that are contributing most to the problem. But these countries, which include the former communist regimes of central and eastern Europe, are also the least able to pay for pollution cleanup and will require substantial economic assistance.

Because the richer countries of Europe will be reluctant to provide this aid, Döös accepts that his lower cost estimate is probably unrealistic. But he does believe that a series of bilateral agreements between European governments could realistically reduce the costs of stabilizing the damage caused by acid rain by $20-30$ per cent.

Döös adds that cutting sulphur dioxide emissions will in the long run have net economic benefits - the benefit to forestry alone would be some $\$ 28,800$ million a year, across the whole of Europe. But governments may still be unwilling to provide massive aid to cut emissions elsewhere without more tangible proof that they themselves will gain economically by doing so. PeterAldhous 